\title{
Greening Bangkok
}

Written by: Clara Young, OECD Observer

Last update: 6 March 2017

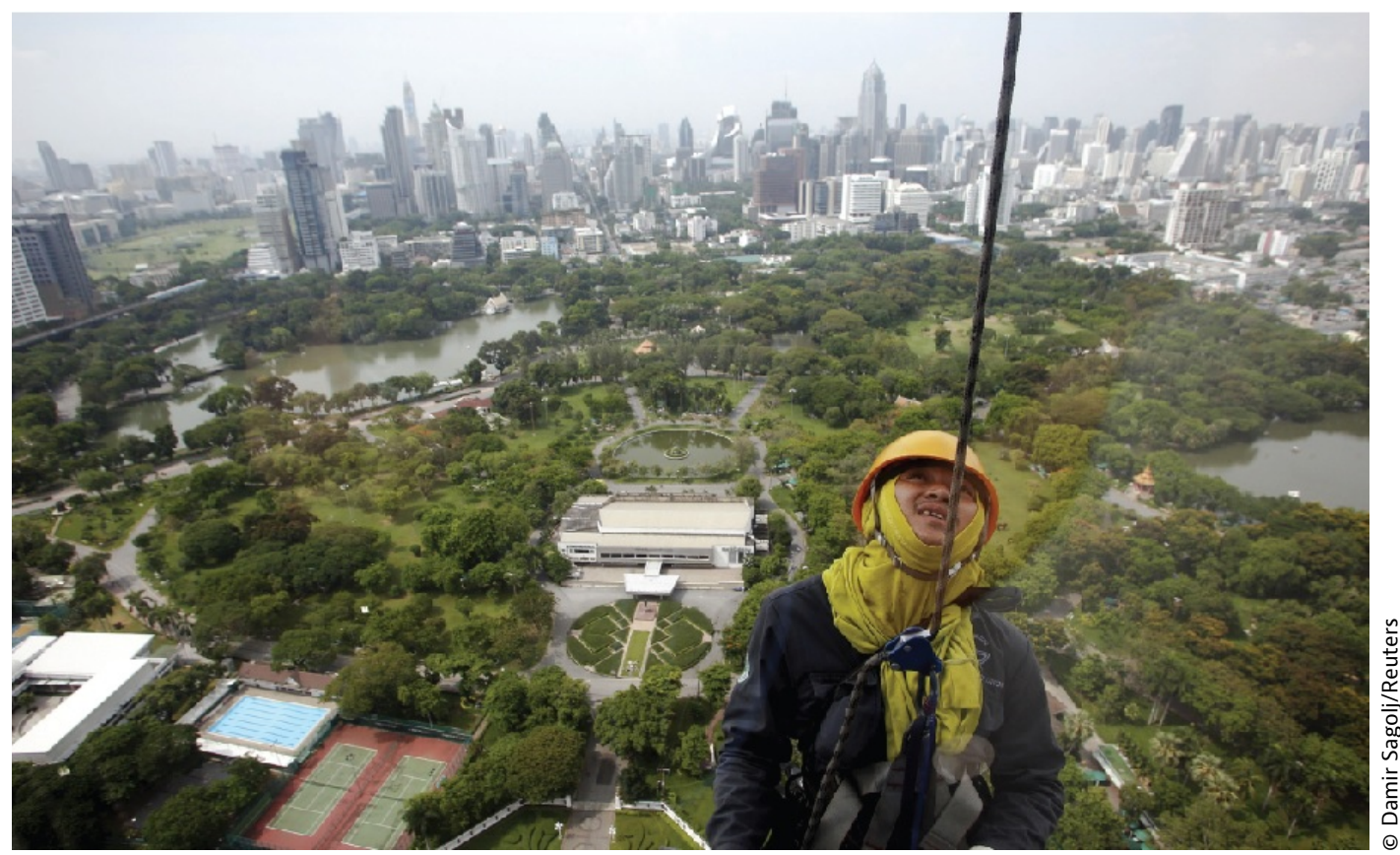

For Thailand's capital of Bangkok, and its surrounding five provinces, green cities are a matter of survival. And with extreme rainfall and summer heatwaves becoming the norm, Bangkok must adapt and develop climate resilience, or risk disappearing.

Bangkok lies in a flood-prone area, which climate change is now rendering more vulnerable. A flood in 2011, the worst in Thailand's history, inundated nearly a tenth of the country, particularly in and around greater Bangkok, and caused over 650 deaths and some US $\$ 50$ billion in damage.

No surprise, therefore, that the Bangkok Metropolitan Region (BMR), which consists of the city of Bangkok and its five provinces, should have a panoply of climate change action plans and green growth strategies. However, most of them focus on policies in the city of Bangkok, and not on the region as a whole. The 2013 Bangkok Comprehensive Plan lays out land-use, infrastructure and transportation plans for the city of Bangkok. Among its green measures, it requires $50 \%$ of open space areas to be given over to vegetation. It also provides incentives for developers to integrate rainwater storage and public parking spaces into new buildings. The 12-year Bangkok Development Plan, which was launched 
in 2009, aims to double the number of public transport users, now at a quite impressive $45 \%$.

Public transport, is, seemingly, one of the BMR's successes in sustainable public infrastructure. Greater Bangkok's network includes a $25 \mathrm{~km}$ elevated rail network (BTS SkyTrain), a 21km underground train network (MRT) and an Airport Rail Link. The Bangkok Metropolitan Authority (BMA) is also attempting to enhance its public transport system with a bicycle-share programme. It recently upped the number of bicycles it provides at stations from 500 to 10,000. Owing to Bangkok's public transport and enforced fuel standards, the city's air quality has improved remarkably in the last 20 years, and its sulphur dioxide and nitrogen dioxide levels meet World Health Organization guidelines.

About $43 \%$ of the city population travels on public transport, with the rest commuting by private cars and motorcycles. This public transport use is higher than many OECD cities, reflecting investment in transit systems. Still, more must be done to lure motorists away from their cars and onto buses, trains, bicycles and canal boats.

In fact, the number of registered vehicles has gone up in Bangkok, almost doubling between 2004 and 2013, while public transport use could descend to 41\% by 2037.

Policies like congestion fees, developing secondary roads and priority lanes for buses, increasing canal transport, and restricting private vehicles in certain zones will help. So will taxing petrol, stopping fiscal incentives for car ownership and ending fossil fuel subsidies. Proper planning in Bangkok's surrounding provinces, where population and employment is growing rapidly, is another way to boost the use of mass transit.

The population of registered inhabitants in greater Bangkok grew by $24.9 \%$ between 2002 and 2013. Manufacturing activities, other than in the textiles industry, have also moved outside the city. This urban sprawl has exacted a high price: developments have depleted forests and natural water retention areas like mangroves and wetlands, making floods increasingly destructive. Sprawl and inadequate affordable housing have also created a substantial slum population; in 2013 , it numbered roughly two million people in the city of Bangkok alone.

Bangkok needs to control peri-urban encroachment through proper land-use zoning. Large residential and commercial buildings in outer Bangkok have sprung up willy nilly. They frequently materialise where there are no links to public transport and public-utility services. A big part of the problem is that decisionmaking on and enforcement of land use legislation is fractured outside Bangkok. The Bangkok Metropolitan Administration governs the city of Bangkok but not the surrounding five (part urbanised) provinces, each of which has its own 
government. Mechanisms should be put in place that enable these local governments to work together, and to co-ordinate with national policies as well.

To see how this might work, take the 2013 Bangkok and Vicinities Development Structure Plan, which is one commission that has harmonised policies between Bangkok and its five provinces. It extended mass transit, conserved wetlands and created floodways through the BMR. Modelled on this kind of co-operation, the BMR should build mixed-use hubs of housing, commerce and employment around public transport stations outside Bangkok. It could make commuting via mass transit more user-friendly. Comprehensive land-use zoning could also protect the remaining green areas, and mandate green, water-absorbent areas in new developments.

Another thing that is going on in the suburbs is the development of solar power plants by private firms. This may be in response to the government's introduction of feed-in tariffs in 2007. Or, it may be prescriptive: with the increase in temperatures, air conditioners pushed electricity consumption up 240\% from 1998 to 2008. Electricity, mostly derived from fossil fuels, is the second source of $\mathrm{CO}_{2}$ emissions in Bangkok. Change is possible: even without much government support for renewable energy sources, solar, wind and biomass made up $11 \%$ of Thailand's final energy consumption (FEC) in 2013. Policy could nudge this higher towards the OECD average share of $15 \%$.

Waste-to-energy incinerators, the first of which is currently being built in Nongkhem, will be another source of energy. They are also a sorely-needed solid waste management method. Bangkok collects about 10,000 tonnes of waste every day. A small percentage is recycled but only through informal community initiatives. Some $90 \%$ goes to landfill, where it moulders away, releasing greenhouse gases (GHG) and ozone-destroying methane into the environment. None of the BMR's solid waste will be properly incinerated until the Nongkhem incinerator comes online. Waste collection and processing is especially problematic in slum areas. And the amount of industrial and household toxic waste is increasing, with much of it not being properly collected or treated.

The BMR needs to concert waste collection and management city and provincewide. It should build more waste-to-energy plants equipped with emission control technology. And it should properly recycle more. While the city of Bangkok started separating solid waste at its source in 2010, the BMR needs to support and expand community-based recycling programmes in the surrounding provinces, perhaps with the Thailand Institute of Packaging and Recycling Management for Sustainable Environment as a model.

Water management from a leaky system also demands action, and the BMR could conserve potable water by improving the network efficiency and adjusting fees to reflect the value of water scarcity, thereby reducing high water-consuming and at 
the same time protecting low-income households through appropriate tariffs and better means-tested subsidies.

Right now, only $46 \%$ of the water used in the city of Bangkok is treated. Industrial and household wastewater goes directly into drainage systems, rivers, canals and the sea, damaging the

only $46 \%$ of the water used in the city of Bangkok is treated ecosystem and polluting freshwater. Bangkok already has monitoring stations along the Chao Phraya River and canals to test water quality and see where water treatment plants need to be placed. The data also tells them who the polluters are. The city and its outlying provinces should require big factories and commercial buildings to connect to the city's wastewater system. Alternatively, industries could develop their own waste treatment facilities with local government regularly monitoring discharges. Furthermore, if the BMR prices wastewater treatment, it will help finance the existing 22 treatment plants and fund new ones.

Protecting green areas, lowering carbon emissions, slowing urban sprawl, conserving water, and cleaning up the waste water system will help the planet. But in Bangkok's case, it will help the city first of all.

\section{References}

Green Growth in Bangkok, Thailand http://dx.doi.org/10.1787/9789264237087-en 